\title{
Libertad versus comercio
}

\author{
Carlos J. Varangot \\ Profesor de la Facultad de Derecho \\ de Buenos Aires. Miembro del Centro \\ Argentino de Altos Estudios Juridicos.
}

I

Durante el siglo pasado, por gravitación del Codigo de Napoleon y la filosofia contenida en las ideas de la Revolución Francesa, los codigos y leyes comerciales tuvieron por comerciante al ser humano, al hombre en si, con abstracción de todos los elementos materiales que ineludiblemente debian participar en el ejercicio de esa profesión.

Esse comerciante individual o colectivo, actuó conforme a normas, usos e ideas de tinte individualista, capitalista y liberal.

A principios del siglo $\mathrm{XX}$, la natural evolución creó fricciones entre la norma escrita y la vida real, en el ambito social, económico y juridico, hasta hacer decir a De Los Rios Urruti, catedrático de Granada: "Estamos "en un momento de honda crisis para la vida politica mun"dial, y esto procede de la decrepitud en que han caido "los principios sobre los cuales ha sido edificado el orden "juridico de nuestra época".

Los problemas sociales y los economicos invadian cada vez más el ambito del Derecho, particularmente del Derecho Comercial, el cual comenzó desde entonces a elaborar nuevas figuras como el: contrato de trabajo y sociedades de responsabilidad limitada. 
Del campo de la Economia recibio el Derecho Comerciale a la Empresa organismo viviente de trabajo y de cosas materiales e inmateriales destinado, en comunión de hombres y de capital, al fin de la economia social, según se ha dicho.

En Alemania: Friedrich Sttzler, Hedemann; en Francia, Paul Durand, Hauriou, Renard, Ripert; en España Joaquin Garrigues; en Suiza, Weiland; y en Italia, Sotgia, Bigiavi, La lumia, Rava, Ascarelli, Asquini, y principalmente LoRenzo Mossa, fueron construyendo paciente $y$ genialmente la sistematica de la empresa, nuevo sujeto del Derecho Comercial.

En 1936 ya se podia considerar consagrada la Teoria de la Empresa en la Doctrina Europea, y en 1942 fue llevada al Derecho Positivo con el Codigo Civil de Italia.

En la Republica Argentina comenzó a divulgarse la Teoria de la Empresa en 1948 sustentandola en la Catedra de la Facultad de Derecho de Buenos Aires a cargo de los Dres. Hernan Maschwitz y C. J. Varangot, en la provincia de Tucuman la expusó el Dr. Arturo de la Vega, y fué también llevada al libro. El Profesor de Derecho Comercial Dr. Alberto Rocamora al informar la Ponencia que sugeria la empresa sujeto del Nuevo Derecho Comercial, en el 2do. Congreso Nacional de Derecho Comercial celebrado en 1953, dijo:

"La empresa se compone de 2 elementos, uno es el ele"mento material, el conjunto de bienes o sea el patrimonio "de la empresa, legislado en algunas leyes (fondo de co"mercio), y el otro es el elemento personal integrado por "el empresario, los auxiliares de comercio, los factores y "demás personas que colaboran en la empresa. El primer "elemento determina la parte estática de la empresa, pero "falta la vida de la misma. Aparece entonces como resul- 
"tante del conjunto de bienes materiales, y de personas, "la empresa como energia viviente, como algo dinámico "que esta aparte de esos bienes materiales".

\section{IV}

Ocurria en la Argentina de esos tiempos: 1953, una evolución economico-social muy favorable a la implantación de la Empresa en el Derecho positivo.

Los obreros nativos se habian organizado en una central sindicalista, el Gobierno creo la Justicia Laboral, fomento la industria y se reglamentaron las instituciones y credito bancario con criterio patriota, diversas leyes ampliaron el control oficial del comercio en protección de la salud del pueblo, se nacionalizaron importantes servicios publicos, se reformó la Constitución Nacional incluyendo clausulas de caracter económico y social, quitandole en lo posible (solo fué una reforma) su matiz individualista, capitalista y liberal que eran reminiscencia de épocas muy pasadas.

Una "nueva manera" social, humanista, popular y cristiana hacia inminente la modificación del Codigo de Comercio y el cambio de sus prescripciones egoistas, liberticidas, absolutistas, capitalistas, pudiendo dar cabida al sujeto Empresa cuyo mecanismo respondia exactamente a la moderna tendencia, pues - como decia Garcia Godoy - es en ella donde se logra que los tres factores clasicos de la producción: naturaleza, trabajo y capital, obren simultaneamente bajo dirección única.

\section{V}

La sublevación militar - que tomo el Gobierno en 1955, - no solo frustró la favorable perspectiva aludida para rejuvenecer la legislación comercial argentina, sino que - entre otras muchas cosas lamentables - posibilitó 
una campaña planeada y en marcha de los capitalistas, quienes percatandose que la Teoria de la Empresa no era propicia a sus fines, resolvieron atacarla, para lo cual se embarcaron en la difusión de lo que denominan la "libre empresa".

No se trata de una simple discrepancia juridica, sino de una divergencia politico-economica tendiente a afianzar un regimen preterito útil a un pequeño sector cuyas prerrogativas necesitan una libertad "absoluta", una propriedad inviolable romanista (cujus est solum, hujus est usque ad coelum et usque ad inferos), libre competencia y libre contratación, limitación de responsabilidad profesional, anonimato en la posesión de titulos, etc.

\section{VI}

Damos al asunto atención, unicamente en su aspecto juridico, prescindiendo del politico.

Vemos asi que, los adictos al llamado Foro de la Libre Empresa, en sus estudios, organizaciones, conferencias y declaraciones denotan tras la apariencia de un criterio de Derecho, una tendencia Economica monopolista contraria a la equidad y al deber de dar a cada uno lo suyo.

Encontramos la denominación libre empresa, solo en dos autores extranjeros; Kennet Cole de los Estados Unidos es uno de ellos, quien concluye que imperando la libre Empresa se reduce al minimo la interferencia del Estado, con lo que pensamos nosotros que la libertad no estara preservada en realidad.

Una declaración del Foro de la Libre Empresa expresa su contrariedad por la creciente intervención estatal del Gobierno depuesto en 1955 y al mismo tiempo celebra el retorno a la libertad; enuncia como "principios": que los consumidores deben recibir creciente afluencia de bienes, que Ias empresas gocen de una efectiva libertad, rechaza 
la unión patronal, y asigna a los trabajadores el derecho de esperar (sic) trabajo bien remunerado.

Se define a la Libre Empresa como el "sistema" que partiendo del reconocimiento de la propriedad privada permite al hombre desplegar todas las fuerzas de su capacidad, de su inteligencia y de su iniciativa para la producción economica, asegurandole el disfrute legitimo de su esfuerzo bajo las garantias y dentro de las limitaciones impuestas por el orden juridico; no quiere que se oriente la economia oficialmente, no quiere que se exproprien o adquieran empresas extranjeras de servicios públicos u otras de interes general, organizó un Instituto de Investigación con comisiones sobre temas agropecuarios, industriales y comerciales, precios y salarios, etc.

Hasta llegaron a organizar un Congreso de Empresarios Catolicos, dandose alli la definición de lo que entienden por salario incentivado, promoción de trabajo, etc. En una conferencia sobre: Responsabilidad del Hombre de Empresa, realizada en la Bolsa de Comercio, se pronosticó para estos "homos economicus" una insospechada relevancia, aconsejandoles atención a la realidad y nuevos factores, $y$ formulandose un calculo de trabajo, utilidad y vida del obrero ( $1 / 2 \mathrm{k}$. de pan: obrero norteamericano 6 minutos, obrero, argentino 11 minutos de trabajo; $1 / 2 \mathrm{k}$. de carne. !!!!!. Se denominó: Frutos de la Libre Empresa, a una disertación que ponderaba a Alemania como el país más libre del mundo desde hacen 10 años, por regir alli la propriedad privada y amplia actividad individual; sin embargo, recordamos nosotros que, leyes anteriores $\mathrm{y}$ posteriores a la ultima guerra organizaron en Alemania las relaciones de empresarios y trabajadores de manera de equilibrar las diferencias posibles entre ambos sectores, y que el Presidente de la Camara de Comercio Alemana en la Argentina, Sr. Thilo Martens observó al orador "libre empresista" que: no se puede aplicar tan facilmente la economia de un país a la economia de otro, como asi también que los capitalistas germanos han puesto 
reparos en traer capital por creer que la Argentina, contrariamente al Brasil, no ha logrado crear un clima apropiado para el inversionista (Diario La Nación, 16-VII1958.).

\section{VII}

Un simple cotejo de las tendencias economicos-juridicas nos muestra a través del tiempo, que, en primer lugar cabe tener presente que ya a principios de la tercera decada de nuestro siglo, leyes, fallos y doctrinas se volvieron contra el regimen Capitalista-Liberal (rebautizado como Libre-Empresa) que lamentablemente aun campea en nuestra Constitución y vetustos Codigos, de modo que los partidarios de la Libre Empresa o Libre Comercio estan en un camino de regreso. $\mathrm{Y}$ esa situación de la tercera decada que invocamos no era una excepción, pues analogas corrientes humanistas aparecieron en Europa y America donde se calificaba al pasado de "espiritu antisocial".

Nadie como el maestro Georges Ripert, en su magnifico libro Aspects Juridiques du Capitalisme Moderne ha fustigado las teorias capitalistas y liberales que se pretende revivir.

En segundo termino, hacemos presente que la Suprema Corte Nacional, de la Argentina, evolucionó en sus pronunciamientos; comenzó con fallos que aceptaban la absoluta validez de las clausulas de la Constitución que prescriben la libertad, la igualdad, la propriedad, etc.

En los casos registrados por la Revista Juridica La Ley, tomo 35, pagina 886, in re: Ramos Mas vs. Gobierno Nacional; tomo 36, pagina 701, in re: Inchauspe Hnos. vs. Junta Nacional de carnes; tomo 37, pagina 561, in re: Martini e hijos; tomo 47, pagina 880 , in re: Castellano Inocencio vs. Quintana Aurelio; tomo 46, pagina 769, in re: 
Gob. Nacional vs. Corporation Arg. de Turismo S.R.L.; tomo 57, pagina 677, in re: Fernandez Fermini; tomo 58, pagina 222, in re: Sociedad de Electricidad de Rosario vs. Gobierno Nacional; tomo 60, pagina 682, in re: Gob. Nacional vs. Del SA.; tomo 72, pagina 99, in re: Cipo s.A. vs. Gobierno Nacional, etc. etc. modificó su abstrusa orientación, y modernizando sus ideas, procuro acomodarlas al ritmo de la vida, y entre otras cosas dijo: que es cuestión admitida que el Estado puede reglamentar $\mathbf{y}$ limitar industrias y actividades; que la garantia de igualdad implica no exigir a unos lo que no se requiere a otros en identicas circunstancias; que los criterios intervencionistas amplio y restringido elige el primero siempre que la ingerencia no sea arbitraria $u$ hostil a personas; que la Constitución no ha reconocido derechos absolutos de propriedad ni de libertad sino limitados; que aunque aquella no haya establecido un ordenamiento económico analogo al prescripto para garantias individuales no cabe concluir que sea imposible desarrollar acción estatal por exigencias contemporaneas, etc.

El Tribunal Superior mencionado, comenzo hace unos 20 años a fundar sus pronunciamientos, apartandose de sus precedentes, en la misión del Estado de defender y afianzar la moral, en la conveniencia colectiva, en el beneficio de la comunidad, en la salud del pueblo, en el orden público, en la seguridad pública, en el bienestar general, en el interes de la comunidad, en la convivencia, en la equidad de compensar la situación de inferioridad de alguna de las partes contratantes, en la defensa de la persona o ser humano, en la represión de estragos económicos, en el justo amparo de la población consumidora, en la tutela de los intereses públicos, etc. En el caso crpo sA. la Sma. Corte dijo hacer una interpretación constitucional fuera del "exajerado individualismo" y atenindose a la interdependencia social. 
Sera tarea del Foro de la Libre Empresa retrovertir los fallos del Superior Tribunal, al que talvez poco le cueste hacer un esfuerzo genetico para practicar un "salto atras" hasta sus antiguos fundamentos, dada su actual composición, fruto de la revuelta militar de 1955.

\section{VIII}

Concluyamos estas lineas señalando que la Teoria de la Empresa (no de la Libre Empresa) encontró en la Argentina, en su jurisprudencia mencionada, en sus leyes progresistas represivas del agio, del monopolio, de fijación de precios, bancarias, doctrina de sus mejores juristas, un campo propicio, y asentó sus fundamentos morales y éticos en los príncipios de la religión cristiana (Enciclicas de Leon XIII, Libertas; la Suma Teologica de Santo Tomas, publicaciones del Dr. Ramella, del Dr. J. Bargallo Crrio, etc.)

Fenomenos de fuerza politico-militares, que alcanzaron a la organización judicial y a la docencia universitaria desviandolas de su misión y afectandolas en su eficiencia, podran demorar la implantación de las normas juridicas modernas, entre estas la de la Empresa, pero no extinguirlas ni desterrarlas, como hacen con las personas desafectas a su credo, el credo de la Libre Empresa.

Cuando nuestro sabio jurisconsulto Lisandro Segovia adornaba una de sus extraordinarias obras con una frase de Vidari, según la cual: en Derecho Comercial, no mudar significa quedarse atras, no penso - y seguramente que tampoco lo pensó VIDARI - que a mitad del siglo XX se propiciara "mudarse para atras" a fin de progresar!

Recordamos haber leido que: "não conduzem os homens aos acontecimentos, mas podem, certamente, por uma pedra ao anteparo de sua marcha"..

Estas lineas son una pequeña "pedra" que enviamos nosotros al paso de una corriente politico-economica contraria al progreso del sentido humanitario en la legisla- 
ción, porque como dice el lema del Centro Argentino de Altos Estudios Juridicos, al que tenemos el honor de pertencer: "jus est ars boni et aequi" -

El mundo no se para, y en su traslación y rotación va modificando invisible y vagorosamente, pero seguramente, los prismas de vida de sus habitantes, dice el inclito maestro de maestros Waldemar Ferreira, y se pregunta ${ }_{\check{C} O u}$ será isso efeito do proprio sol?. No sabemos responderle al dilecto amigo e insigne jurista, si el eterno cambio obedece al sol, pero.. rogamos a Dios que no obedezca a la Libre Empresa!. 